\title{
THESES
}

\section{Post-dural puncture headache: clinical characteristics and diagnostic criteria (abstract)}

\author{
Cefaleia pós-punção dural: características clínicas e critérios diagnósticos (resumo)
}

\author{
Jane Auxiliadora Amorim \\ Universidade Federal de Pernambuco - UFPE. Pós-graduação de Neuropsiquiatria e \\ Ciências do Comportamento (área de concentração: Neurociências). PhD Thesis. 2012. \\ Orientador: Marcelo Moraes Valença
}

Amorim JA. Post-dural puncture headache: clinical characteristics and diagnostic criteria (abstract).

Headache Medicine. 2012;3(3): 100

Background and objectives: The diagnostic criteria for post-dural puncture headache (PDPH) of the International Classification of Headache Disorders (ICHD-II, 2004) state that postural headache appears not later than the fifth day after the puncture and disappears spontaneously within a week, or within 48 hours after treatment with an epidural blood patch. The criteria also necessarily include at least one of the following symptoms: neck stiffness, tinnitus, hearing loss, photophobia, and nausea. In this study, we evaluated the clinical features of PDPH and the validity of diagnostic criteria (ICHD-II, 2004).

Methods: Over one year, 640 patients (332 women and 308 men) aged between 8 and 65 years underwent spinal anesthesia, with Quincke needles, 25G $(n=239)$ and $27 G$ $(n=401)$. The onset of postural headache, i.e., when the pain worsens or appears after sitting or standing, was investigated through daily visits to patients and/or phone contact for seven days after anesthesia. Among the patients who had PDPH the following characteristics were evaluated: (1) the latency period between the dural puncture and the onset of headache, (2) the location and intensity of pain, 3) accompanying symptoms, and (4) the duration. The procedures for descriptive statistics were used measures of central tendency: mean, dispersion (standard deviation and variation amplitude) and frequency distribution. The chi-square test was applied and considered statistically significant when $p<0.05$. This study was approved by the Ethics Committee in Research and informed consent was obtained from patients or their legal guardians.

Results: 48 patients (7.5\%) had postural headache. The latency period ranged from 6 to 72 hours ( $24.0 \pm 16.8$ hours) and the duration from 3 to 15 days ( $4 \pm 2$ days). Pain was reported in the following regions: occipital, 26 (54\%); frontal, 19 (40\%); and holocranial, $3(6 \%)$. In $85 \%$ of patients the intensity of the headache was moderate or severe. 14 of the 48 patients (29.2\%) had no accompanynig symptoms.

Conclusions: Our results are not in consistent with the ICHD-II diagnostic criteria; we thus suggest a number of changes in the diagnostic criteria. 